\title{
Ureteral Triplication and Contralateral Duplication with Vesicoureteral Reflux
}

\author{
Haluk Söylemez¹, Mustafa Koplay², Bülent Altunoluk³ , Fatih Oğuz \\ ${ }^{1}$ Clinic of Urology, Special Müjde Hospital, Malatya, Turkey \\ ${ }^{2}$ Department of Radiology, Faculty of Selçuklu Medicine, Selçuk University, Konya, Turkey \\ ${ }^{3}$ Department of Urology, Faculty of Medicine, Sütçü Imam University, Kahramanmaraş, Turkey
}

\begin{abstract}
Ureteral triplication is a rare congenital anomaly of the urinary tract. Since its first description, only about 100 cases have been reported in the literature. The association of ureteral triplication and contralateral duplication is even rarer. We reported a case of ureteral triplication and contralateral duplication with vesicoureteral reflux. The patient was a five-year-old girl with a history of recurrent urinary tract infections, dysuria and lower abdominal pain. Intravenous Pyelography (IVP) showed duplication of the right ureter and triplication of the left ureter. In the cystourethrogram there was vesicoureteral reflux at the lower pole of the right kidney. The patient underwent right lower to upper ureteroureterostomy and excision of the distal ureter. This is the second report of ureteral triplication in Turkey. The literature concerning this rare anomaly was reviewed.
\end{abstract}

Key Words: Urogenital abnormality, vesico-ureteral reflux, ureteral triplication

Received: 20.03 .2010

Accepted: 02.07.2010

\section{Introduction}

Although ureteral duplication is rather common, ureteral triplication is a rare congenital anomaly of the urinary tract. Duplication of the ureter is always coexistent with duplication of the kidney. Since the first description of ureteral triplication by Wrany in 1870, only about 100 cases have been reported in the literature. Pediatric cases are rare, and it occurs in females more often (1). In this report, we presented a patient with ureteral triplication and contralateral ureteral duplication. Additionally, there was a vesicoureteral reflux on the duplicated side.

\section{Case Report}

A five-year-old girl with a history of recurrent urinary tract infections, dysuria and lower abdominal pain was referred to our department. On physical examination, the body temperature was $37.2^{\circ} \mathrm{C}$. There was no abdominal tenderness and rigidity. White blood cell count was increased $\left(15.7 \times 10^{9} / \mathrm{I}\right)$ in the routine blood examination. Urine analysis showed many leukocytes and erythrocytes. Ultrasonography showed bilateral duplication of the renal pelvis and lower pole hydronephrosis of the right kidney. The patient was given intravenous antibiotics until the urinary tract infection was controlled and urine analysis returned to normal. An intravenous pyelography (IVP) was then performed. The IVP showed duplication of both the right ureter and renal pelvis. Also, it showed triplication of the left side. On the right side, the lower pole of the renal pelvis and ureter were dilated (Figure 1). Therefore a voiding cystourethrogram was performed. On the cystourethrogram, there was a vesicoureteral reflux at the lower pole of the right kidney. There was no reflux on the left side. Two ureteral orifices were seen on both sides of the bladder by cystoscopy. Right retrograde pyelography showed that the ureter from the lower pole was inserted superiorly and laterally to the ureter from the upper pole (Weiger-meyer Law). Left retrograde pyelography showed type II ureteral triplication according to Smith's classification (Figure 2) (2). The patient electively underwent right lower to upper ureteroureterostomy and excision of the distal ureter of the lower pole. She had a complete recovery.

\section{Discussion}

Ureteral duplication is a very common anomaly of the ureter, but triplication of the ureter is quite rare. Since the first description of ureteral triplication by Wrany in 1870, about one hundred cases have been described in literature (1). This congenital anomaly is due to the presence of three buds from the mesonephric duct or two buds with early fission of one of them. The presence of two buds from the mesonephric duct and premature fission of a single bud can explain the occurrence of double and bifid ureters $(1,3)$.

Ureteral triplication is divided according to Smith's four grade classification into; type 1: three ureters from the kidney, with three draining orifices to the bladder (complete triplication), type 2: three ureters from the kidney with two draining orifices (incomplete triplication), type 3: three ureters from the kidney with only one draining orifice (trifid ureter), type 4: two ureters 


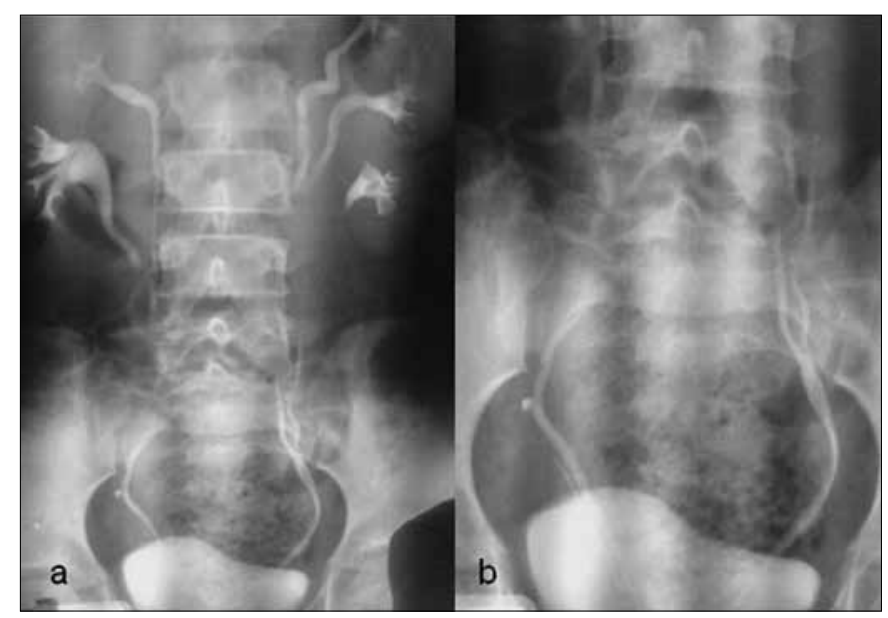

Figure 1. Intravenous Pyelography of the patient. 1-A: Left ureteral triplication with right ureter duplication and dilated lower pole of right kidney. 1-B: Cropped and enlarged version of figure $1 \mathrm{~A}$

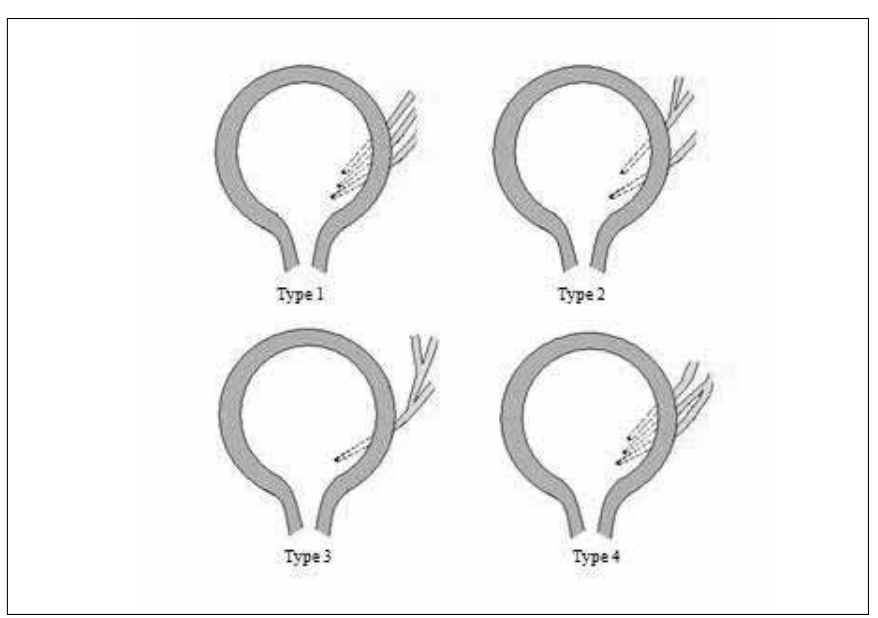

Figure 2. Smith's classification of ureteral triplication (2)

from the kidney, one of which becomes an inverse Y-bifurcation, resulting in three draining orifices below (Figure 2) (3). A triplication of the ureter with a blind proximal end of one, diagnosed on retrograde pyelography, was described without any reference to Smith's classification (4).

The presenting symptoms are the same as in duplication; urinary tract infection, urinary incontinence and flank or abdominal pain. Incontinence is usually an evidence of ureteric ectopia (5).

In most cases, ureteral duplication is unilateral. Occasionally, it is bilateral. However, bilateral ureteral triplication is rarer than bilateral ureteral duplication. Only 5 cases of bilateral ureteral triplication have been reported (6). Furthermore, ureteral triplication is occasionally an isolated anomaly (7). It has been reported in the literature that ureteral triplication may be complicated with contralateral ureter duplication, vesicoureteral reflux, ureterocele, crossed ectopic fused kidneys, ureteropelvic obstruction and duplication of the bladder $(6,8)$. In addition, ureteral quadruplication has been described and it is an extremely unusual developmental abnormality (9). In our case, there was ureteral triplication with contralateral ureteral duplication. At the same time, renal pelvises were triple on the left side and were duplex on the other. Additionally there was a vesicoureteral reflux on the lower pole of the duplicated side. The triplicated side was not accompanied by any other urinary tract pathology. Therefore, we operated only on the duplicated ureter which caused the vesicoureteral reflux.

All of these variable conditions should always be considered once ureteral triplication has been diagnosed and every patient with ureteral triplication requires an individual strategy for management and treatment.

The basic problem of triplication is its own correct diagnosis, because it occurs in different forms, and it may be misdiagnosed as duplication. Usually it is detected incidentally during surgery and autopsy. Ultasonography and computed tomography are useful in the diagnosis of triplex ureters, but intravenous pyelograpy may be more useful in completely defining the abnormal anatomy (10). In the differential diagnosis of congenital anomalies of the urinary tract, especially when recurrent urinary tract infection, reflux, hydroureteronephrosis or urinary incontinence are present, ureteral triplication should be considered along with the other anomalies.

\section{Conflict of Interest}

No conflict of interest was declared by the authors.

\section{References}

1. Bouhafs A, Dubois R, Chaffange P, Laboure S, Valla JS, Dodat $\mathrm{H}$. Two rare case reports of ureteral triplication. Ann Urol 2002;36:42-4. [CrossRef]

2. Smith I. Triplicate ureter. Br J Surg 1946;34:182-5. [CrossRef]

3. Kudela G, Koszutski T, Mikosinski M, Utrata W. Ureteral triplication-report of four cases. Eur J Pediatr Surg 2006;16:279-81. [CrossRef]

4. Hsu TH, Goldfarb DA. Blind-ending ureteral triplication. J Urol 1998;159:1295. [CrossRef]

5. Fernbach SK, Poznanski AK. Pediatric case of the day. Complete ureteral triplication. Radiographics 1989;9:359-64.

6. Li J, Hu T, Wang M, Chen S, Huang L. Ureteral triplication: the first report in China. J Pediatr Surg 2004;39:38-9. [CrossRef]

7. Singh G, Murray K. Ureteral triplication, occasionally an isolated anomaly. Urol Int 1996;56:117-8. [CrossRef]

8. Sivrikaya A, Cay A, Imamoglu M, Sarihan H. A case of ureteral triplication associated with ureteropelvic junction obstruction. Int Urol Nephrol 2007;39:755-7. [CrossRef]

9. Vicentini FC, Denes FT, Srougi M. Ureteral quadruplication associated with ureteral cyst and massive vesicoureteral reflux treated by laparoscopic nephroureterectomy. J Endourol 2007;21:769-71. [CrossRef]

10. Ochoa Urdangarain O, Hermida Pérez JA, Montes de Oca JO, Miranda Rosales F, Rivero García C. Complete triple ureter. Case report. Arch Esp Urol 2006;59:284-7. 